\title{
Tobacco dependence treatment: scientific challenges; public health opportunities
}

\author{
Jack E Henningfield
}

This is an exciting time to be involved in tobacco control efforts. We have scientifically based tools and strategies that can reduce disease and prolong the productive lives of current tobacco users. We better understand the pressures on young people to take up tobacco use and how to prevent dependence from developing. Thanks to the investigation of the Food and Drug Administration (FDA) in its tobacco rule making effort, and litigation against the industry, ${ }^{12}$ we have fresh insights into how the tobacco industry maximises its deadly effectiveness as a vector to spread the disease of tobacco dependence. These understandings are no less profound or important in efforts to control tobacco caused diseases than is scientifically based knowledge about how to control other global maladies such as malaria, in which understanding the pathogenesis of the disorder led to breakthroughs in how to prevent its spread and treat those afflicted. ${ }^{3}$ As with malaria, we also are learning that prevention and treatment go best when hand in hand. It is also clear that, as difficult as it is to control the proliferating mosquitoes that spread malaria, controlling the tobacco industry, which spreads tobacco dependence, is even more difficult in many respects because it enjoys many legal protections and enormous political power. But here is the opportunity for managed care to make a difference.

Managed care has the potential to help break the cycle of tobacco dependence, and thereby address the needs of its individual members, while also helping to control the epidemic. But treatment benefits that are not utilised do not improve public health. In this article, I will highlight aspects of the tobacco addiction process that have implications for developing treatment benefits which could make a difference to the health of managed care members and to the health of the nation.

\section{If treatment is offered will the benefit be utilised?}

I have had numerous discussions with health care providers who expressed concern that if tobacco dependence treatment were offered as a substantial benefit, it would be overwhelmed by applicants and could "break the payer's bank". I believe that the real problem is just the opposite, namely that unless creative approaches are taken to encourage tobacco dependent people to utilise the benefit, it will be so underutilised that neither individual managed care members, nor the health of our nation, will be improved by the offering. Nonetheless, a revealing question that tobacco treatment advocates in a managed care organisation might ask of their organisation is the degree to which they intend the benefit to be utilised, because the structure of the benefit would be expected to influence strongly its utilisation. Managed care organisations may vary in the degree to which they are willing to provide a tobacco treatment benefit. For example, those with a high turnover of young males may be less likely to see cost recovery than those with women at prime child bearing years or those with lower turnover rates of adults in whom disease risk is rapidly accelerating.

There is also a wide range of reasons for individuals not to participate in treatment. The first is related to the addictive process itself which includes physiologically based drives that lead to denial by those afflicted that they need treatment, and fear that they will lose the control that their smoking has provided them over body weight, mood, stress, and mental function. Social pressures, often from former smokers who quit without formal assistance, codify falsehoods (for example, the best way to quit is cold turkey and all you need is to "set your mind to it"). Treatment promotion is countered by a multibillion dollar effort by the tobacco industry to "delay the quitting process" and "keep smokers in the franchise as long as possible", and compete against treatment. ${ }^{4}$ Treatment utilisation is also limited because the treatments are not nearly as attractive from an image perspective (the medications are not hyped, for example, as gateways to sexual encounters) nor pharmacologically engineered to maximise pleasure and addiction (ammonia additives, acetaldehydenicotine combinations, and the use of deadly, albeit effective tar particles sized to maximise deep lung exposure are not permitted for medications as they are for cigarettes). ${ }^{5}$

The bottom line of the foregoing observations is that the barriers that managed care organisations often use to prevent popular benefits from being over utilised and inappropriately utilised may serve to prevent many of those most in need from ever utilising this benefit. Or, if the benefit is utilised, it may not lead to the maintenance of long term remission from their dependence because the jhenning@

pinneyassociates.com

J E Henningfield
Research and Health Associates, Inc, 4800 Montgomery Lane, Montgomery Lane,
Suite 1000, Bethesda Suite 1000, Beth 
nature of the treatment offering was not acceptable or did not permit long term application, even where the need was medically justified. For example, requiring participation in group counselling may preclude more than $90 \%$ of those interested in treatment from obtaining it because of their disdain for the group process. Requiring patients to pay out of pocket for medications, which require point of sale purchases of $\$ 20$ to $\$ 40$, provides an unbearable financial barrier for many, regardless of whether they will be eventually reimbursed. Moreover, financial barriers appear to target selectively lower income smokers because tobacco dependence has become more prevalent in lower income Americans. By contrast, most smokers purchase their cigarettes in increments of approximately $\$ 2$ per pack, with lower cost "generic" brands taking an increasing share of the market of adult lower income smokers who consider a $\$ 20$ carton of cigarettes to be a luxury.

Some plans do not include FDA approved over the counter (OTC) nicotine gum and patch, or require patients to pay out of pocket for these medications. This is inconsistent with the facts that such medications are similarly effective as prescription patches and bupropion, and that the OTC products provide differences in nicotine delivery characteristics and dosing schedules that might make them preferred to some smokers. ${ }^{5}{ }^{6}$ The OTC products also include extensively developed behavioural support packages. Finally, one of the more widely accepted medicine types, nicotine gum, is only available as an OTC medication.

Limitations on duration of use and how many courses of treatment can be obtained may effectively prevent some individuals who have been able to achieve tobacco abstinence from sustaining abstinence. The fact is that currently available diagnostic methods cannot predict, a priori, how long and how many times an individual will need to be treated. Therefore, from a medical perspective it makes the greatest sense to provide access to treatments along a similar model as medications to treat diseases, which are often the result of untreated tobacco dependence (for example, heart disease), in which the medications are provided as needed to control symptoms and prolong life.

\section{Individual and public health benefits of tobacco dependence treatment}

It is accepted almost to the point of cliche that every effort should be made to prevent future generations from developing tobacco dependence and suffering the ravages of tobacco caused disease. But how many truly accept former surgeon general Koop's admonition to "don't forget the smokers"? ${ }^{7}$ What are the consequences of "forgetting the smokers" and what is our responsibility as health professionals to current tobacco users? These questions may be considered at both the individual and the population level.

At the individual level, it is now clear that the health benefits of cessation are profound. The pregnant woman who stops smoking early in pregnancy reduces the risks of complications to about those of a never smoker, and the risk of cardiovascular disease is sharply reduced within six months to two years of abstinence. ${ }^{8}$ The risk of many other diseases, absenteeism at work, and possibly even sickness in non-smoking children, also are reduced within one year of smoking cessation. ${ }^{9}$ Finally, even among smokers who have developed a debilitating tobacco caused disease, their symptoms, suffering, prognosis, and overall life expectancy can be improved by smoking cessation. ${ }^{10}$ The foregoing is scientifically supported, and stands in contrast to the apparent beliefs of many smokers that the damage is already done and if a disease has developed "at least I will be more comfortable being able to smoke". Effective offering of a tobacco dependence treatment benefit could help many individuals realise real health benefits and improved quality of life.

At the public health level as well, managed care has the opportunity to make an enormous difference. Figure 1 illustrates the current course of tobacco caused deaths and the opportunity to make a difference by treatment and prevention efforts.

\section{Easy to get the disease, hard to get the treatment: the FDA's dual strategy}

Former FDA commissioner, Dr David Kessler, set the FDA on a course that began to address the problems graphically illustrated in the figure. Specifically, the Kessler approach set the FDA on a course to reverse the situation, described by Koop ${ }^{7}$ and others (for example, Warner $e t a l^{11}$ ) as easy to get the disease and hard to get the treatment. In 1996, the FDA took two major actions. One was the issuing of the "final rule" to regulate cigarettes and smokeless tobacco products as "combination drugs and drug delivery devices", which enabled the FDA to begin the process of reducing access and appeal to tobacco product toxins. The other action was approving three nicotine replacement medications (gum and two brands of transdermal patch) for OTC marketing, which was a significant step toward reducing barriers to treatment availability.

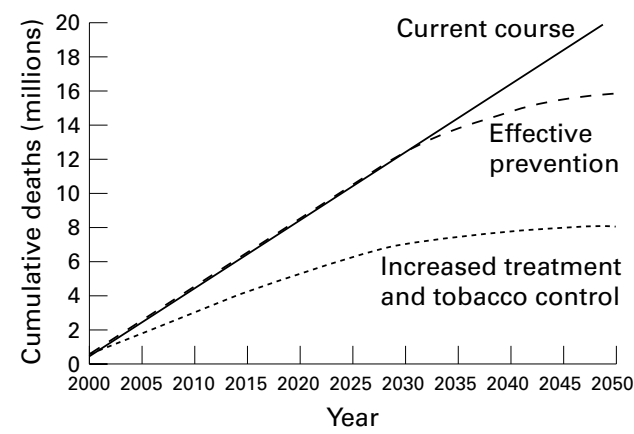

Figure 1 Projections of smoking caused mortality based on present trends (current course) compared to projections of no new smokers (effective prevention), and projections in which smoking exposure at the individual and population level is reduced (increased treatment and tobacco control). Reproduced from Henningfield and Slade ${ }^{5}$ with permission of The Food and Drug Law Institute. 
FDA'S TOBACCO RULE

In essence, the focus of the tobacco rule was to begin to make tobacco products less appealing and less accessible to children and adolescents, and eventually adults. ${ }^{12}$ The core conclusion that enabled the FDA to assert jurisdiction was that nicotine in cigarettes and smokeless tobacco products is a drug and that these products are nicotine delivery devices. The combination drug device status not only meets the reality of the products, but it also provides the FDA with much greater regulatory flexibility to, for example, exert controls over product dosing and labelling without banning it as might be required if the products were simply categorised as drugs. With a goal of reducing tobacco caused death and disease, but without banning cigarettes per se, the FDA then designed a program that was youth focused in its efforts to reduce access (for example, by preventing underage tobacco sales) and appeal (for example, by prohibiting advertising in youth focused magazines). But it also recognised that many other serious issues needed to be addressed because of their adverse health effects. For example, the FDA recognised that the Federal Trade Commission (FTC) monitored tar and nicotine rating system for cigarettes was flawed, and rather than providing incentives for less toxic cigarette design, was actually enabling cigarette manufacturers to undermine prevention and cessation programs with so called reduced tar and nicotine cigarettes ("lights"). These products were designed to cheat the smoking machines while giving smokers much higher levels of toxins than advertised. The FDA also recognised that many advertising strategies were tantamount to unregulated marketing claims related to the pharmacologic effects of nicotine (for example, images implying weight loss, control of stress and boredom), and that certain cigarette additives and manufacturing techniques brought cigarettes and smokeless tobacco to unprecedented heights in addiction potential.

In short, although the tobacco rule was youth focused, the tobacco industry was correct in its concern that the FDA had the knowledge and potential power to bring about radical changes in the way it developed and marketed products. I believe that we need to see to it that the FDA becomes fully empowered to regulate tobacco products; the FTC does not have the expertise or authority to regulate appropriately the design, manufacture, dosing characteristics, additives used, labelling, or implied claims in advertising and trademarks of cigarettes. The current primary regulatory authority for cigarettes, the Bureau of Alcohol, Tobacco and Firearms, may be outstanding in bomb detection and halting lead contamination of alcohol, but contamination of cigarettes with high nitroasamine yielding burley tobacco, arsenic, and aflatoxin ${ }^{13}$ appears well outside its area of expertise, as this is not a health oriented agency.
OTC NICOTINE REPLACEMENT MEDICATIONS About the same time that the FDA was conducting its tobacco investigation and developing its tobacco rule, it had before it applications for approval to market nicotine gum and two brands of nicotine patches as OTC products. The politically easy course with these applications probably would have been to delay, if not outright deny, them as it might have appeared inconsistent to some to "promote" these forms of nicotine while discouraging others. Yet Kessler and other key individuals at the FDA understood that, from a health perspective, that was precisely what was needed: make it tougher to get the disease causing form of nicotine delivery while making it easier to get the forms that were proven to reduce toxin exposure, enable cessation, and thereby save lives.

The OTC process involves more than simply eliminating the need for prescriptions. The FDA took it as an opportunity to encourage the companies to support their products with labelling and consumer guidance that provided the essentials of treatment. They encouraged three special populations-adolescents, pregnant women, and persons with active heart disease - to consult with health professionals before using the products, though the labelling was intended to not discourage them unduly from seeking these or other forms of treatment. The FDA required the marketers to maintain other standards for marketing that would serve long range public health interests, including providing surveillance to detect unintended consequences such as youth abuse. On the other hand, by operating within these constraints, the marketers had greater flexibility to market not only the products, but also the concept of treatment itself as a legitimate, desirable, and "normal" activity for smokers to consider. One result was that companies worked not only to garner market share but also foster increases in general smoking cessation activity as a means to grow the treatment market.

\section{PUBLIC HEALTH IMPACT}

Both aspects of the FDA's dual approach appear likely to make important contributions to public health. For example, portions of FDA's tobacco rule followed precedents taken by the states of Massachusetts and California, which had earlier implemented their own tobacco prevention programs. These programs included more aggressive enforcement of youth tobacco purchasing bans and advertising restrictions. Although caution must be taken in extrapolating from these state efforts to the FDA's approach, especially since the FDA's program has been narrowly focused to date on youth procurement bans, it is nonetheless encouraging that tobacco use rates in adults and youth have declined in these states, relative to use rates in the nation as a whole. ${ }^{14}{ }^{15}$

With respect to the OTC switch of gum and patch, the most important conclusions might be those issued in the Morbidity and Mortality Weekly Report of the Centers for Disease Control and Prevention as part of an analysis of the 
increased smoking cessation activity on the occasion of the Great American Smoke Out (GASO): "The findings of this report suggest that the GASO promotional campaign and OTC availability of nicotine medications encouraged smoking cessation activity." And further: "Marketing and promotion efforts designed to promote attempts to quit, along with OTC availability of nicotine mediations, are a useful part of a national strategy to reduce the prevalence of smoking." ${ }^{16}$ Moreover, it was more recently estimated that overall successful cessation of tobacco use in the United States was increased by $10-25 \%$ above that which would have occurred had the products remained available by prescription only. ${ }^{17} \mathrm{Tak}-$ ing a somewhat different analytical approach, Lawrence et al projected increased smoking cessation and associated life expectancy gains due to the increased treatment utilisation resulting from OTC nicotine medications. ${ }^{18}$ The estimates of these studies depend upon various assumptions; however, sales trends since 1997 suggest that the contribution of OTC medications to national smoking cessation activity has increased beyond the projections of Shiffman et al in $1997^{17}$ and Lawrence et al in $1998 .^{18}$ The point of this discussion is not that OTC medications provide a total solution; they are still unacceptable, inaccessible, or unaffordable to many smokers. Rather, this experience demonstrates the principle that increasing the access and appeal of treatment can contribute to increased cessation and improved public health. Managed care could extend the effort.

Although interpretations of the consequences of FDA's dual approach must be made with caution appropriate to the available data, the conclusion appears inescapable that when pressures mount to discourage smoking, while simultaneously providing more accessible treatment options, more people try to quit smoking and more people actually quit smoking. Managed care organisations have the potential to take such successes to an even higher level and thereby contribute to the health of their members as well as to that of the United States as a whole. Managed care organisations could provide their members with motivational materials on the benefits of smoking cessation and the availability of treatment and then actually make treatment more accessible. Effecting such a course, however, will be complicated by the addiction process itself, as well as tobacco industry marketing as discussed below.

\section{Tobacco products and marketing as impediments to treatment utilisation} Cigarettes are not simply rolls of fine tobacco in pristine paper, and tobacco product marketing is not just a means to hold cigarette brand share among adults who would be smoking anyway. Tobacco products are the most toxic and addictive of all nicotine delivery systems, with cigarettes arguably being the worst, because they both require and reinforce deep inhalation of smoke into the lungs. Virtually every conceivable, and many previously incon- ceivable, manipulations have been done to maximise the ability of the cigarette to cause addiction, even though many of those manipulations involved sustaining if not increasing certain toxicological consequences. ${ }^{2} 4$

The modern cigarette is a highly engineered dosing system that is used to meter doses of nicotine to consumers, ensuring that consumers can get their desired level of nicotine from virtually any cigarette on the market, regardless of its machine derived tar and nicotine rating. Although the tobacco industry disputed the FDA's conclusion that cigarettes were drug delivery devices, their own scientists and senior staff understood the concept in great detail. ${ }^{19}$ Philip Morris's William Dunn said it clearly: "The cigarette should be conceived not as a product but as a package. The product is nicotine. Think of a puff of smoke as the vehicle of nicotine. Smoke is beyond question the most optimised vehicle of nicotine."

Cigarette design is integrated with market driven goals - for example, the need for brands with lower tar and nicotine to "reassure smokers", the need for brands with "smoother" smoke apparently to addict more readily young people (with one such message bluntly pitched by "smooth" Joe Camel). Responding to consumer concerns about tar and nicotine, manufacturers incorporated elaborate engineering technologies ranging from control of particle size to ammonia additives and hidden ventilation systems, to produce cigarettes that would provide lower tar and nicotine ratings in machine tests while actually enabling the delivery of much higher levels to consumers. ${ }^{2}{ }^{419-21}$ Unfortunately, in the process of obtaining levels of nicotine to sustain their addictions, consumers also achieve much higher levels of carbon monoxide and toxic "tar" than claimed, and by the process of inhaling more deeply into the lungs, which may be facilitated by a less harsh feeling smoke by many light cigarette brands, the smokers may be increasing their risk of adenocarcinomas. ${ }^{22}{ }^{23}$ These brands use labels and advertising that rely upon terms that consumers have come to expect to imply are meaningful because of the restrictive and regulated use of such terms with respect to foods and beverages. Thus, terms such as "light", "lower", "reduced", and "ultra light" are used in advertisements and labelling. These terms sometimes are incorporated into trademarked brands, which make it particularly difficult for the FTC to control. Aggressive marketing of such brands has led to their domination of the United States tobacco market and has been attributed to thwarting tobacco control efforts to reduce smoking cessation activity and smoking prevalence. ${ }^{24}$

More than six billion dollars were spent in 1998 to market tobacco products. This has included some of the most aggressive and creative marketing aimed at enticing new customers, holding on to customers who would like to quit, and competing with the growing treatment industry. ${ }^{25}$ Moreover, as restrictions such as the ban on large billboards imposed by the Master Settlement Agreement 
are effected, creative new ways to market products have emerged such as the aggressive pushing of cigarette smoking and sales in nightclubs and other social venues targeting young adults. It is telling that only about $10 \%$ of tobacco marketing funds were spent on advertising in 1998 with the remainder going to other marketing techniques aimed at aggressively keeping existing smokers smoking and increasing the pipeline of new smokers. The amount of resources and range of acceptable techniques to encourage smoking cessation and treatment utilisation pales by any measure, but this only increases the need for managed care organisations to attempt creative ways to stimulate and facilitate tobacco cessation activity.

A Philip Morris marketing analysis of competition for its tobacco products included nicotine patches, gum, and other treatments. ${ }^{26}$ British American Tobacco considered entering the transdermal patch market as a means to hold its share of the nicotine delivery business, but opted not to in part because of legal concerns as well as its conclusion that the patch provided such a slow form of nicotine delivery that its market potential was not viewed as significant enough. ${ }^{27}$ Thus, tobacco product marketing may be considered direct competition for treatment providers - as it is by the tobacco industry - and managed care organisations may need to consider their own marketing techniques if they intend for a treatment benefit to be utilised.

Tobacco dependence as an impediment to treatment utilisation

Tobacco dependence is a chronic relapsing disorder which might be thought of like the bonsai tree which is raised with wire constraintseven after the wiring is removed, the tree is forever changed. Most people start smoking during very active years of physiological and psychological development. ${ }^{28} 29$ Smoking becomes a means to modulate mood, to reduce anger, stress, boredom, and weight, as well as to sustain concentration and other cognitive functions. ${ }^{29}$ By the age of 18 years, most smokers regret ever having started and $50 \%$ have tried to quit. Subsequently, most smokers will attempt abstinence repeatedly, but in the absence of treatment their success rates are so low that approximately $50 \%$ will experience premature death. ${ }^{30}$

The term "tobacco addiction" is used much as the term "cancer" is used as a more generally understood term to describe disorders that may actually be defined, diagnosed, and treated according to guidelines that use more precise terminology. With respect to tobacco addiction, two specific medical disorders may exist and be treated separately, although most commonly they co-exist and are co-treated ${ }^{31}$ : (1) nicotine dependence is the disorder of maladaptive and seldom remitting tobacco use; (2) nicotine withdrawal is the constellation of withdrawal symptoms that accompany tobacco abstinence in a person who has been chronically exposed to nicotine. The occurrence of withdrawal symptoms reflects the development of tolerance and physical dependence upon nicotine such that physiological dysfunction occurs when nicotine is abruptly withdrawn. Although animal studies have shown it is possible to develop dependence and withdrawal syndromes when only pure nicotine is administered, ${ }^{32} 33$ tobacco delivered nicotine preparations are the only forms of nicotine that have ever been documented to lead readily to chronic use and dependence. ${ }^{28}$

The risk of developing dependence following exposure to cigarettes is greater than the risk of developing dependence following initial use of cocaine, alcohol or marijuana. ${ }^{34}$ In addition, a person smoking a little over a pack of cigarettes a day may take 100000 puffs per year or a million puffs in 10 years. This is part of the basis for a powerfully engrained behaviour. By contrast, Pavlov's dog only took a few pairings of the bell and the food to develop a strong conditioned behavioural and physiological response. Some effects of this process may become very long lasting, if not permanent, as they include changes in brain function (for example, altered brain electrical, metabolic and neurohormonal activity) and brain structure (for example, increased numbers of functional brain nicotine receptors). ${ }^{28}$ How many smokers will need extended, or even life long, nicotine or other treatments because of their many years of smoking? In the absence of an answer to this question, should treatment be limited to an arbitrary duration?

A core premise, then, is that cigarette smoking in most smokers is sustained by an acquired need, which we call dependence or addiction, to self administer nicotine from cigarettes. Most smokers are addicted and meet diagnostic criteria for the medical disorder known as dependence in the Diagnostic and statistical manual of the American Psychiatric Association. ${ }^{31}$ The physiological basis of addiction is what the director of the National Institute on Drug Abuse, Dr Leschner, referred to as the "changed brain". The changed brain is also the physiological basis for treatment. As Leschner concluded: "Addiction, including nicotine, is fundamentally a brain disease." The problem is, it is not just a brain disease. Addiction itself is actually a result of a combination of environmental factors, historical factors, and the physiological state of the individual (for example, their genetic background). They all come together through the brain to produce addiction. ${ }^{35}$ So, the drug defines the addiction, but addiction is more than just a drug. Effectively preventing and treating addiction entails more than just understanding what goes on in the brain. It often requires social encouragement, individualised support, and ready access to intervention approaches.

An implication of these observations is that, if a given managed care organisation actually intends for the tobacco treatment benefit to be utilised, it will have to address the needs and desires of its members creatively. It will need to recognise that the dependence process itself stands as a barrier to the willingness of patients 
to seek treatment, and that the tobacco industry is actively competing to keep its customers smoking cigarettes. A treatment benefit may require its own marketing strategy that takes into account the propensities of an addicted population or it will be so underutilised that the potential contribution to overall health will not be realised.

\section{Current treatment: benefits and limitations}

In the United States, during the 1980s, only about 3\% of smokers annually achieved the milestone of having sustained abstinence for one year; one year abstinence achievement in unaided quitting efforts ranges from about 3-8\%. ${ }^{28} 36{ }^{37}$ Pharmacological treatments, and some behavioural treatment modalities, approximately double the odds of successful abstinence with better results generally accompanying treatment efforts that are more intensive and individualised. ${ }^{36} 3839$ Moreover, as demonstrated in the Puget Sound study of more than 90000 enrollees to health plans which differed widely in the conditions of their coverage for nicotine replacement medications, it was found that utilisation was highest in plans that provided "full coverage" as opposed to plans that required members to pay a share of the cost. ${ }^{40}$ Although smoking cessation rates were slightly higher in those who paid a portion of the medication's cost, the authors concluded that the higher rates of utilisation of the "full" benefit still led to higher overall levels of smoking cessation and were cost effective.

Thus, whether or not treatment works, or can contribute to public health when made more accessible, are no longer core questions. The big question is how do we make tobacco dependence treatment even more accessible and acceptable? Of course this question leads to many proposals, including developing even more acceptable treatments (for example, more palatable nicotine forms) and treatment applications and indications (for example, to treat withdrawal and reduce exposure to toxins in those who are not ready or willing to abstain completely from tobacco).

When considering the likelihood that cigarette smokers will readily accept currently available treatment strategies, it is worth keeping in mind Oscar Wilde's description of smoking. He said: "A cigarette is the perfect type of perfect pleasure. It is exquisite and leaves one unsatisfied. What more could one want." ${ }^{41}$ One of the many implications of these observations for designing treatment benefits that are acceptable to smokers is that currently available treatments are a long way from providing comparable pleasure and satisfaction to smokers. This conclusion is also consistent with the competitive analyses of treatment from the tobacco industry mentioned earlier in this article. ${ }^{2627}$

Compared to cigarettes, available treatment approaches leave many avenues of potential satisfaction unfilled. Behavioural therapies do not provide the pharmacological aids to control of mood, body weight, or boredom. Medications do not simulate smoking or provide the sensory effects to which the smokers have become accustomed over hundreds of thousands, if not millions, of puffs from cigarettes. Moreover, pure nicotine, even if given as explosively fast and at the highest doses possible from cigarettes, probably would not completely substitute for the effects of tobacco delivered nicotine, which include the enhancement of effects by chemicals ranging from ammonia compounds to produce free base nicotine, to acetaldehyde and monamine oxidase inhibiting substances that may also contribute to the persistence of smoking. ${ }^{125}$ As summarised by Warner et al, ${ }^{11}$ nearly all aspects of the design, labelling, marketing, and regulation of tobacco products tilt the playing field preferentially toward cigarettes, and away from treatment products.

In addition to the limitations posed by the nature of the treatment products, their sanctioned uses (that is, their indications) are also limiting. Tobacco users report a wide range of reasons for use, and tobacco companies imply a wide range of reasons for use. However, treatment products are medically indicated for one purpose: smoking cessation for the treatment of tobacco dependence. This limited indication ignores the fact that the primary purpose of treatment is to reduce death and disease and that cessation may be only one means to that end. ${ }^{42}$ In fact, discussions of tobacco dependence typically invoke the term "cessation" or "cessation programs" rather than the term "treatment". Even though tobacco use cessation should be the long term primary goal, there may be other equally valid goals and treatment strategies. ${ }^{57}$

Presently, for people who are currently unwilling or unable to abstain completely from tobacco, there is no FDA approved treatment. The tobacco industry has rushed to fill this need with deadly "light" cigarettes with none of the barriers facing pharmaceutical companies that might attempt to develop effective toxin reduction strategies. ${ }^{5}$ Although many people now work in settings in which smoking may be prohibited, and in which their withdrawal symptoms might compromise their performance and pose a hazard to others, using medications to relieve withdrawal symptoms and enable optimal performance is not medically indicated, even though the scientific evidence for at least the nicotine delivering medications indicates that they are effective in this application. ${ }^{28}{ }^{43}$ Even though medications are approved for maintenance in persons who need longer term help for disorders ranging from depression, anxiety, hypertension, opioid dependence, and many other disorders, medications for smoking cessation are not labelled for such use and I am not aware of a managed care organisation providing for such use. None of the foregoing potential applications are without some controversy or should be implemented without careful consideration, ${ }^{58}$ yet failure to attempt to implement more creative approaches to address the needs of patients will leave many with no viable alternative to smoking until their 
deaths, incurring substantial medical expenses along the way.

\section{Conclusions: designing benefits that will be used}

Treating tobacco dependence is like treating malaria in a mosquito infested swamp or cocaine addiction in a crack infested neighbourhood. Smokers and former smokers live in a world infested with professional promoters of smoking. They have ready access to the products and recurrent exposure to relapse inducing tobacco smoke and stimuli provided by marketing. Plus, their bodies might be physically crying out for their favourite form of nicotine. By their nature and application, existing treatments do not compete well for smokers who have spent years being satisfied by their best friend, the cigarette.

Barriers to treatment utilisation, as seemingly well intentioned as making sure that smokers are committed to treatment by having them pay for their preferred medications out of pocket, only to be reimbursed later (perhaps only with documentation of non-smoking status), will effectively prevent many smokers from being treated. Other constraints on medication use are at odds with our understanding of the tobacco dependence process as a chronic relapsing disorder, not unlike hypertension, in that treatment may need to be individualised and sustained for months, if not years, and need to be reinstated according to the medical needs of the patients.

A lesson learned from the GASO experience discussed above ${ }^{16}$ is that finding innovative ways to encourage smokers to attempt cessation while simultaneously making treatment more accessible can inspire high rates of aided quitting. How this is accomplished in managed care settings may not be simple, and will probably vary according to the population served and other aspects of the plan itself, but the conclusion that emerges is that treatment utilisation probably can be facilitated by attending to the needs of those who are in need. It should not be the case that the most seemingly interested party that many smokers see is their tobacco company and not their health care organisation.

The health of the managed care members, and the health of America, might be served best by a dedication of managed care organisations to offer not only a treatment benefit, but treatment benefits that will be utilised by as many tobacco users as possible. An understanding of the addictive process itself might serve health care providers in their efforts to provide treatment services, even as such an understanding has previously served tobacco companies to keep their customers until death parts the relationship. This area of health promotion poses substantial challenges, but harbours an enormous opportunity for managed care to contribute to public health.

1 Kessler D, Witt A, Barnett P, et al. The Food and Drug Administration's regulation of tobacco products. $N$ Engl $\mathcal{F}$ Med 1996;335:988-94.
2 Hurt RD, Robertson CR. Prying open the door to the tobacco industry's secrets about nicotine. $7 A M A$ 1998; tobacco indust

3 Miller LM. The challenge of malaria. Science 1992;257:368.

4 Slade J, Henningfield JE. Tobacco product regulation: context and issues. Food and Drug Law fournal 1998; 53(suppl):43-74

5 Henningfield JE, Slade J. Tobacco dependence medications: public health and regulatory issues. Food and Drug Law Fournal 1998;53(suppl):75-114.

6 Hughes JR, Goldstein MG, Hurt RD, et al. Recent advances in the pharmacotherapy of smoking. $7 A M A 1999 ; 281: 72-$

7 Koop CE. Don't forget the smokers. The Washington Post 1998, March 8:C7.

8 US Department of Health and Human Services. The health benefits of smoking cessation. A report of the Surgeon General, benefits of smoking cessation. A report of the Surgeon General, 1990. Rockville, Maryland: Public Health Service, Centers for Disease Control, Office on Smoking and
(DHHS Publication No (CDC) 90-8416.)

9 Henningfield JE, Ramstrom LM, Husten CG, et al. Smoking and the workplace: realities and solutions. fournal of Smoking-Related Disorders 1994;5(suppl 1):26170.

10 Browman GF, Wong G, Hodson I, et al. Influence of cigarette smoking on the efficacy of radiation therapy in head and neck cancer. N Engl F Med 1993;328:159-63.

11 Warner KE, Peck CC, Woosley RL, et al. Treatment of tobacco dependence: innovative regulatory approaches to reduce death and disease. Food and Drug Law fournal 1998;53(suppl): $1-9$

12 Kessler DA, Natanblut SL, Wilkenfeld JP. Nicotine addiction-a pediatric disease. $\mathcal{F}$ Pediatr 1997;130:518-24.

13 Lane KS. Aflatoxin, tobacco, ammonia, and the p53 tumorsuppressor gene: cancer's missing link? Medscape General suppressor gene: cancer's missing link? Medscape
Medicine (www.medscape.com), August 30, 1999.

14 Pierce JP, Gilpin EA, Emery SL, et al. Has the California tobacco control program reduced smoking? $7 A M A$ 1998;280:893-9.

15 Harris J, Connolly G, Davis B. Cigarette smoking before and after excise tax increase and anti-smoking campaign in Massachusetts, 1990-1996. MMWR 1996;45:966-70.

16 Centers for Disease Control and Prevention. Impact of promotion of the Great American Smokeout and availability of over-the-counter nicotine medications, 1996. MMWR 1997;46:867-71.

17 Shiffman S, Gitchell J, Pinney JM, et al. Public health benefit of over-the-counter nicotine medications. Tobacco Control 1997;6:306-10.

18 Lawrence WF, Smith SS, Baker TB, et al. Does over-thecounter nicotine replacement therapy improve smokers life expectancy? Tobacco Control 1998;7:364-8.

19 Food and Drug Administration. Regulations restricting the sale and distribution of cigarettes and smokeless tobacco to protect children and adolescents; final rule. Federal Register 1996;61:44395-5318.

20 Slade J, Bero LA, Hanauer P, et al. Nicotine and addiction. The Brown and Williamson documents. FAMA 1995; 274:225-33.

21 Food and Drug Administration. Regulations restricting the sale and distribution of cigarettes and smokeless tobacco to protect children and adolescents; final rule. Federal Register 1995;60:41314-787.

22 Hoffmann D, Hoffmann I. The changing cigarette, 1950-1995. F Toxicol Environ Health 1997;50:307-64.

23 Thun MJ, Day-Lally CA, Calle EE, et al. Excess mortality among cigarette smokers: changes in a 20 -year interval. Among cigarette smokers: changes in

24 Giovino GA, Tomar SL, Reddy MN, et al. Attitudes, knowledge, and beliefs about low-yield cigarettes among adolescents and adults. In: The FTC cigarette test method for determining tar, nicotine, and carbon monoxide yields of US cigarettes: report of the NCI expert committee. Washington, DC: National Institutes of Health, National Cancer Institute (NIH Publication No. 96-4028, 1996.)

25 Lubove S. Brand Power. Forbes August 9, 1999:99-104.

6 Reuter B. Competitive analysis. Philip Morris secret internal document (coded 19717).

27 Hwang SL, Freedman AM. BAT considered patches but stuck to making cigarettes. The Wall Street fournal, October 9, 1995, B3.

28 US Department of Health and Human Services. The health consequences of smoking: nicotine addiction. A report of the Surgeon General, 1988. Rockville, Maryland: Public Health Service, Centers for Disease Control, Office on Smoking and Health, 1988. (DHHS Publication No (CDC) and Health,

29 US Department of Health and Human Services. Preventing tobacco use among young people. A report of the Surgeon General, 1994. Atlanta, Georgia: Public Health Service, Centers for Disease Control and Prevention, Office on Smoking and Health, 1994. (US Government Printing Office Publication No S/N 017-001-00491-0.)

30 Peto R, Lopez AD, Boreham J, et al. Mortality from smoking in developed countries 1950-2000: indirect estimates from national vital statistics. New York: Oxford University Press, 1994.

31 American Psychiatric Association. Diagnostic and statistical manual of mental disorders, $4^{\text {th }}$ ed (DSM-IV). Washington, DC: American Psychiatric Association, 1994.

32 Corrigall WA. Nicotine self-administration in animals as a dependence model. Nicotine \& Tobacco Research 1999; 1:11-20. 
33 Stolerman IP. Interspecies consistency in the behavioural pharmacology of nicotine dependence. Behavioural Phar-

34 Henningfield JE, Schuh LM, Heishman SJ. Pharmacological determinants of cigarette smoking. In: Clarke PBS, Quik M, Adlkofer FX, Thurau K, eds. Effects of nicotine on biological systems II, International Symposium on Nicotine, Advances in Pharmacological Sciences. Switzerland Birkhauser Verlag, 1995:247-56

35 Leshner A. Moyers on addiction: close to home [transcript]. PBS television. March 29, 1998 .

36 Henningfield JE. Nicotine medications for smoking cessation. N Engl F Med 1995;333:1196-203.

37 Shiffman S, Mason KM, Henningfield JE. Tobacco dependence treatments: review and prospectus. Ann Rev Public Health 1998;19:335-58.

38 Fiore MC, Bailey WC, Cohen SJ, et al. Smoking cessation. Clinical Practice Guideline No 18. Rockville, Maryland: US Department of Health and Human Services, Public Research, April 1996. (AHCPR Publication No 960692.); < http://www.text.nlm.nih.gov/ftrs/tocview>.

39 Hurt RD, Dale LC, Offord KP, et al. Serum nicotine and Hurt RD, Dale LC, Offord KP, et al. Serum nicotine and
cotinine levels during nicotine-patch therapy. Clin Pharmacol Therapeutics 1993;54:98-106.

40 Curry SJ, Grothaus LC, McAfee T, et al. Use and cost effectiveness of smoking cessation services under four insurance plans in a health maintenance organization. $N$ Engl $f$ Med 1998;339:673-9.

41 Moyer DB. The tobacco almanac: a reference book of facts, figures, and quotations about tobacco Washington DC: US
Government Printing Office, Publication No. 1998-783-000-88020; 1998:28.

42 Schuh LM, Henningfield JE. Nicotine replacement treatment and public health interventions: toward a marriage of
two approaches. In: Slama K, ed. Tobacco and health: two approaches. In: Slama K, ed. Tobacco and health:
proceedings of the Ninth World Conference on Tobacco and proceedings of the Ninth World Conference
Health. New York: Plenum Press, 1995.

43 Fiore M, Shi FY, Heishman SJ, et al. The effect of smoking and smoking withdrawal on flight performance. Report to Centers for Disease Control and Prevention, National Center for Chronic Disease Prevention and Health Promotion, Office on Smoking and Health, 1994.

\section{Questions and answers}

Q: Your introductory comment was, "Are managed care entities going to be tempted to provide only minimal intervention?". The Agency for Health Care Policy and Research guidelines say the more intensive the treatment, the better the outcome. Yet I know from experience in the Veteran's Administration, and from watching managed care, that there is a tremendous temptation to use the least effective method and to say programs are provided. What is your opinion of the trend here?

A: As you know, it is easy to provide a smoking cessation benefit at some level. The question is how extensive, how flexible, how adaptive, how recurring should it be? Again, the big question facing managed care is do you really want people to use the benefit? How many people do you want to use it? Here again, the situation is complicated. If you are in an organisation that has a turnover every year, there is probably less of an incentive to provide the benefit than in an organisation that cares for people for a longer period of time. However, if you want people to utilise the benefit, you have to market it. You have to market it as aggressively as the tobacco industry markets, because they are going to do everything possible to keep people out of treatment, in order to keep their customers "in the franchise" as long as possible.

Q: Cessation, of course, would be a universally acceptable end point. To what extent is harm reduction becoming acceptable by tobacco addiction specialists?

A: This is one of the trickiest areas to address. The Public Health Service recognised in 1964 that the risk of cancer and other diseases is related to the amount of exposure to tobacco byproducts. That observation led to the government promoting the idea that if you cannot quit, less is better. The problem is that the tobacco industry beat the system. They came up with cigarettes that were rated lower; but they did it by cheating the measurement machines, by putting in hidden ventilation holes, by hiring particle physicists to make sure that a higher proportion of particles get deep into the lungs, by using additives such as ammonia. It is amazing how they beat the system to give two thirds of American smokers what they believed were lower risk cigarettes. With respect to the tobacco industry, we need to do everything possible to understand the products better. Where there is evidence that a product does not have to be as harmful-for example, where we can remove cyanide or carbon monoxide - we need to set standards. In Sweden, they figured out 20 years ago how to reduce the nitrosamines drastically in smokeless tobacco products. Our companies have not done that. There is no government standard for nitrosamines. We could establish a standard next year. The Swedes have demonstrated that it is commercially and technically feasible.

What the tobacco industry wants, however, is an incentive that says "Let us label our products as less harmful". That is where it gets complicated. In my opinion, if we do that, we are interfering with treatment and cessation. Our response to the tobacco industry should be, "Here is the new standard. You cannot make any claim - this is the standard". Over the years, we should be doing everything possible to reduce the toxicity. We have talked about taking the nicotine out to reduce addictiveness. By the same token, we should keep a broad view of treatment. Cessation should be our highest goal. Everyone should be accountable in the effort to achieve that goal, whether it is the treatment provider, the pharmaceutical company, or the tobacco company. But we should explore the development of treatments to reduce tobacco toxin exposure that do not undermine prevention and cessation.

Q: Regarding teens and cessation, is there a role for nicotine replacement therapy? What are the obstacles, and should we be examining this issue?

A: There has been limited work on teens and cessation, period. The 1994 surgeon general's report highlighted that deficiency. The Centers for Disease Control and Prevention is one of the organisations that is now taking an active role in the development of teen treatment. The FDA's paediatric rule which requires all drug manufacturers to look at paediatric applications for all new drugs will have an impact. The current labelling of OTC products states "Not to be purchased by people under 18 years of age" but this does not preclude their use. There are a lot of specialists doing work with youth and medications. There is, I think, every reason to think that youth are treatable. 